\title{
A DEFINIÇÃO DE SIMPLICIDADE NA FASE ITALIANA DE LINA BO BARDI
}

Maria Izabel Rego Cabral/UFPE

Virgínia Pereira Cavalcanti/UFPE

\section{RESUMO}

Lina Bo Bardi foi uma importante incentivadora da arte popular e da arquitetura e design modernos no Brasil. Graduada pela Universidade de Roma em 1939, atuou em seus primeiros anos de carreira em editorias de revistas em circulação em seu país de origem, a Itália, no contexto histórico marcado pela Segunda Guerra Mundial. Enquanto ganhava espaço no meio profissional, mostrou um amadurecimento intelectual e político em seus escritos, que mostram o desenvolvimento de um lado humanista que a marcaria em toda a sua vida. Observou-se o recorrente uso da palavra simplicidade e derivados, o que é entendido neste estudo como reflexo do modernismo apreendido por Lina durante a sua formação. Sendo assim, este artigo objetiva definir as manifestações de simplicidade presentes em artigos escritos pela arquiteta durante o período italiano (19401946). O estudo é de natureza qualitativa e o corpus é composto por alguns desses artigos, escritos originalmente em italiano, e embasado por revisão de literatura acerca do Racionalismo italiano e biógrafos de Lina Bo Bardi.

Palavras-chave: Simplicidade; Lina Bo Bardi; Racionalismo Italiano; História do Design.

\section{Introdução}

Lina Bo Bardi (1914-1992) foi uma relevante arquiteta e designer ítalo-brasileira que viveu de sua infância ao início da vida profissional na Itália das duas grandes guerras mundiais. Graduada em Arquitetura em Roma em 1939, mudou-se para Milão no ano seguinte, a convite do colega de profissão Carlo Pagani, com quem fez uma importante parceria profissional. Através de Pagani, trabalhou com Gio Ponti, diretor de revistas que discutiam a casa. Algumas dessas tinham como público-alvo as mulheres donas de casa que começavam a entrar no mercado de trabalho; outras, eram direcionadas aos leitores arquitetos, escritas com linguagem técnica.

Devido à escassa demanda de projetos, o trabalho desenvolvido por arquitetos envolvia a elaboração de ilustrações e artigos. E não foi diferente com Lina Bo. Entre 1940 e 1946, colaborou com revistas, entre elas Bellezza, Cordelia, Grazia, Vetrina e Negozio, Tempo, L'Illustrazione Italiana, Lo Stile e Domus, e para o jornal Milano Sera, e nove edições da revista $A$ Cultura della vita - sendo esta última uma iniciativa sua em parceria com Bruno Zevi e Pietro Maria Bardi. Na dissertação defendida em 2017 pela autora deste artigo, dispôs-se de 136 desses artigos, todos escritos em italiano, 15 dos quais foram selecionados e traduzidos pela mesma. Não somente nos 15 artigos, mas em muitos deles existe um tema abordado frequentemente: a simplicidade (CABRAL, 2019). 
De acordo com Abbagnano (2007), Mora (1984) e Pallasmaa (2014), a simplicidade está associada filosoficamente à economia de formas, à redução de um problema nas menores partes possíveis e à redução da complexidade. Assim, pode-se relacioná-la ao Racionalismo, corrente filosófica que prioriza a razão como caminho para alcançar a verdade, e considera a dedução como um método superior de investigação filosófica. O Racionalismo filosófico foi a base para o surgimento da corrente arquitetônica de mesmo nome, na década de 1920, como um dos pilares do movimento moderno arquitetônico (BENEVOLO, 2009).

Diante do exposto, este trabalho, que compila resultados parciais da pesquisa de doutorado em curso no Programa de Pós-Graduação em Design da Universidade Federal de Pernambuco - UFPE, tem como objetivo definir as manifestações de simplicidade presentes em artigos escritos por Lina Bo Bardi durante o período italiano (1940-1946). O estudo é de natureza qualitativa e o corpus é composto por artigos de revista originais, escritos por Lina ainda na Itália, traduzidos pela autora deste trabalho, e é embasado por revisão de literatura acerca do Racionalismo italiano, sob a ótica de BENEVOLO (2009) e FRAMPTON (2000), e pesquisadores da obra de Lina Bo Bardi, entre eles FERRAZ (2018), GRINOVER (2018) e LIMA (2021), entre outros.

\section{A Simplicidade Racionalista}

O legado cartesiano definido por Descartes no século XVII foi aplicado como método na Arquitetura no século XIX, através do arquiteto francês Viollet-le-Duc. Em seu Discurso Sobre a Arquitetura, usou o método cartesiano no sentido da apropriação de um esquema que estabelecesse um modelo epistemológico relativo à prática arquitetônica, à estruturação e aplicação de um método claro e objetivo. Para o arquiteto, faltava uma metodologia que se adequasse ao processo de desenvolvimento de projetos arquitetônicos, e para isto o método analítico de Descartes foi tido como ideal.

A metodologia projetual leduciana é resultado do processo reflexivo acerca do racionalismo associado ao uso de linguagem de desenho técnico, representada por plantas, fachadas, cortes e perspectivas. Para le-Duc, tanto a prática quanto a história da arquitetura pressupunham um método e uma metodologia, e ainda não havia uma teoria definida de forma clara que os contivesse (AMARAL, 2007). Como esta metodologia poderia simplificar o projeto? Para Viollet-le-Duc, o uso da razão deveria ser o ponto de partida deste método, seguido de uma divisão do problema em partes menores, e cada parte deveria seguir uma sequência de raciocínio linear e crescente, de forma dedutiva. Assim, literalmente desenvolveu uma equação matemática que continha passos que deveriam ser seguidos em ordem durante o processo criativo do arquiteto: 
1) Dividir o processo projetual em partes, diminuindo, assim, a complexidade do todo: Definição do programa $\rightarrow$ Escolha das técnicas e materiais construtivos $\rightarrow$ Visualização da lógica estrutural $\rightarrow$ elaboração do desenho arquitetônico.

2) Dispor esses elementos na equação matemática: $P+M=D$ (sendo $P$ o programa, $M$ as técnicas e materiais construtivos e $D$, o desenho arquitetônico).

O programa é o conjunto sistematizado de necessidades de um determinado uso de uma edificação, ou seja, a sua função; já o desenho representa a forma desta edificação. Sendo assim, entende-se que o método de Viollet-le-Duc precede o postulado da teoria funcionalista da arquitetura moderna, expressa pelo paradigma $A$ forma segue a função (AMARAL, 2007).

O racionalismo tal qual se conhece na Arquitetura moderna surgiu na Europa no início do século XX como desdobramento da metodologia de le-Duc e da estética cubista. Possui diferentes vertentes em cada local: o racionalismo ideológico do Construtivismo russo, o racionalismo formal corbusiano na França e o racionalismo empírico dos países escandinavos, por exemplo. Na Alemanha, o racionalismo metodológico-didático foi marcado pela experiência da Bauhaus, fundada por Walter Gropius em 1919 na Alemanha, que foi decisiva para o desenvolvimento da tendência racionalista no campo da arquitetura e do design. O vocabulário formal adotado pelos arquitetos dessa geração incluía o uso sistemático de formas puras e elementares na composição arquitetônica e de design, de modo a obter simetria e equilíbrio, bem como a utilização de linhas retas, novos materiais, estrutura aparente, cobertas planas e ausência de ornamentos, que constituem pontos centrais do racionalismo moderno (BENEVOLO, 2009; FRAMPTON, 2000).

\section{Aproximação biográfica: a fase italiana}

Na Itália, os debates arquitetônicos no início do século XX ocorriam entre Roma e Milão. Em Roma, centro político do fascismo, os debates aconteciam em torno de referências clássicas, condizente com o nacionalismo e desejo de imponência do regime. Em Milão, os debates eram majoritariamente de cunho progressista, e foi onde surgiu o racionalismo italiano, em 1926, a partir do Gruppo 7 - um grupo de arquitetos que criaram um movimento pela renovação estilística da arquitetura italiana. 


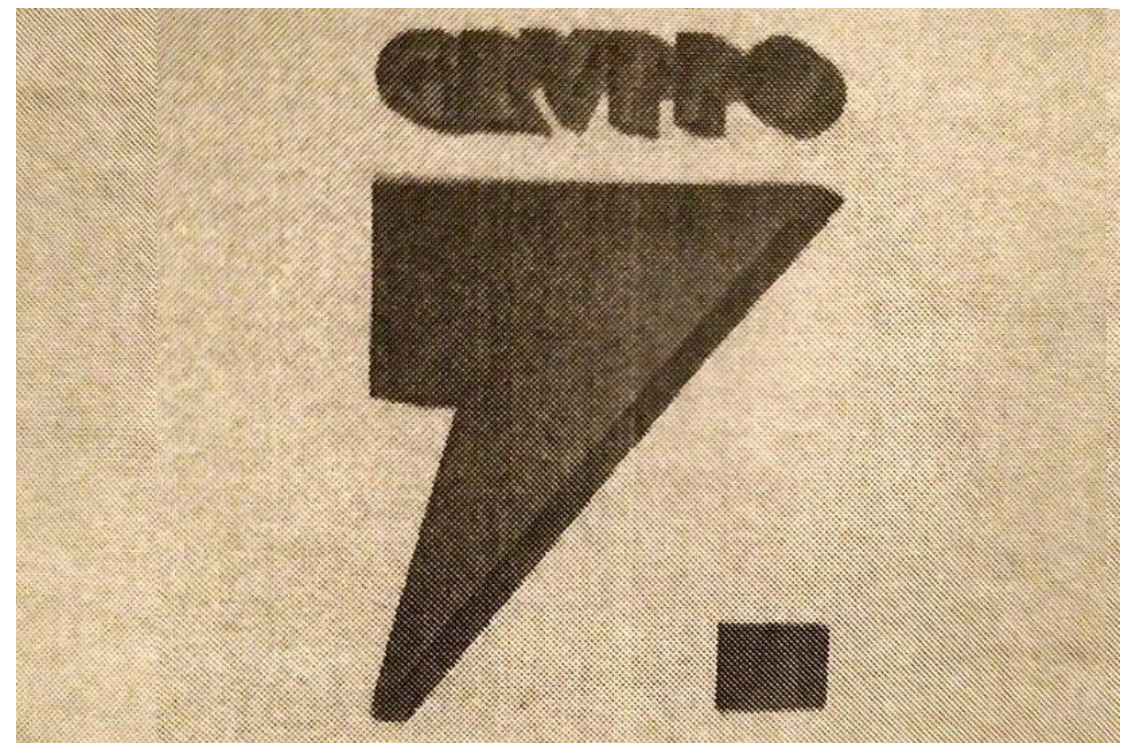

Figura 1. Logotipo do Gruppo 7.

Fonte: Manifiesto del Gruppo 7, Arquitectura. https://tecnne.com/tag/gruppo-7/.

O racionalismo italiano ficou caracterizado como um movimento contraditório: inicialmente, foi apontado pelo grupo de arquitetos do Movimento Italiano per l'Architettura Razionale (MIAR) - um grupo de jovens arquitetos atentos às experiências contemporâneas europeias que eram promotores da arquitetura moderna na Itália - como única expressão capaz de manifestar os valores e princípios fascistas. Posteriormente, o racionalismo deu lugar ao estilo Lictório, mais condizente com a arquitetura monumental pretendida por Mussolini para Roma, passando a ser adotado entre os arquitetos orientados politicamente contra o fascismo, tornando-se mais próximo ao cunho progressista do modernismo existente em outros países da Europa (BENEVOLO, 2009; CABRAL, 2019).

Lina Bo viveu em um contexto social, histórico e político de uma Itália dominada pelo fascismo, cenário que teve implicações em sua formação profissional e intelectual. Durante a graduação, lidou com o fato de ser uma das poucas mulheres que estudavam na universidade e com a misoginia de alguns mestres. Ao final do curso, projetou um hospital de linguagem arquitetônica racionalista, o "Núcleo Assistencial da Maternidade e da Infância" (que passou a chamar de "maternidade para mães solteiras"), inspirado nas arquiteturas de Luigi Piccinato e de Alvar Aalto. O seu diploma de arquiteta foi entregue pelo professor Marcello Piacentini, que a haveria questionado se um dia lhe seria útil (ANELLI, 2010; CABRAL, 2019; LIMA, 2021). 


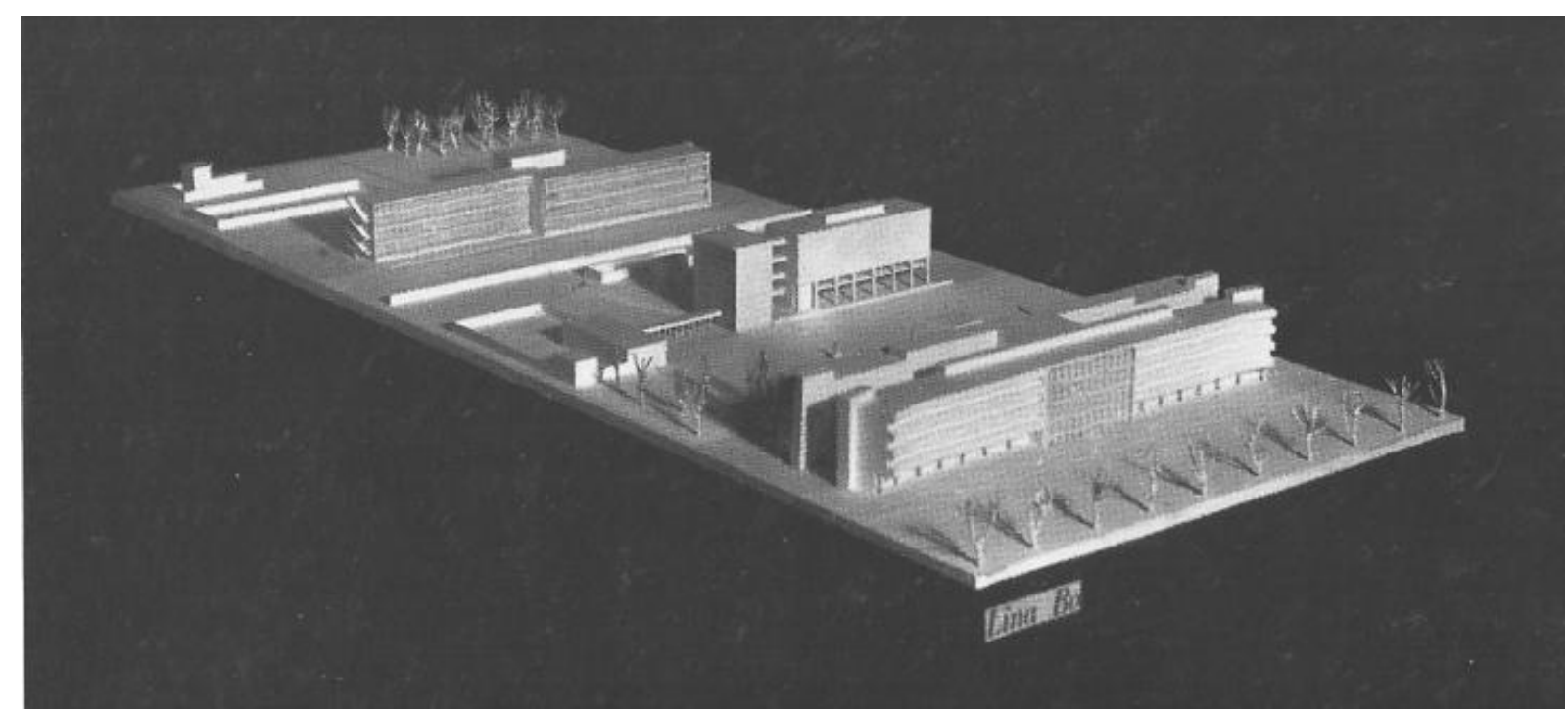

Figura 2. Maquete do projeto de graduação elaborado por Lina Bo Bardi. Fonte: FERRAZ, 2018

O período de estudos na universidade conferiu uma forte base teórica à arquiteta, especialmente nas áreas de restauro, história e representação arquitetônicas, conhecimentos que seriam essenciais para o desenvolvimento de sua carreira no Brasil. A sensibilidade e o olhar atento de Lina para o que acontecia ao seu redor a fazia se questionar sobre "as ruínas recuperadas pelos fascistas" de Roma (LIMA, 2021, p. 67), percepção que a fez mudar-se para a capital da Lombardia em 1940, quase sem o apoio da família.

A nova etapa de sua vida em Milão Ihe trouxe uma visão humanista e ampliou seus horizontes, sendo o ambiente ideal para que ela adquirisse a independência que almejava desde sempre. Neste início, montou um pequeno escritório na Via Gesù com Carlo Pagani, demonstrou interesse em trabalhar como desenhista para o arquiteto Giuseppe Pagano - envolvido com o movimento racionalista italiano e diretor da revista Casabella, começou a lecionar no programa de arquitetura do Politecnico de Milano e começou a trabalhar de forma independente para seu ex-professor de projeto de interiores, Gio Ponti - que, por sua vez, liderava o movimento que propunha a integração entre artesanato e design industrial italianos (LIMA, 2021). As experiências e o contexto histórico vividos em Milão seriam o pano de fundo para as expressões de Lina sobre o movimento moderno e, de forma recorrente, sobre a simplicidade.

\section{O Simples como forma de expressão na fase italiana}

A recém-formada Lina Bo iniciou seu trabalho como ilustradora e escritora em editorias de revistas em 1940, sob a chefia de Gio Ponti. Os primeiros artigos foram escritos para revistas direcionadas para as donas de casa, e orientavam de que forma a manutenção do ambiente doméstico se tornaria mais prática, principalmente a partir da aplicação de determinados materiais. Nas entrelinhas, havia 
a intenção de formação do gosto moderno, que expressava um espírito de época e começou a ser difundido entre os racionalistas por Edoardo Persico (1900-1936), crítico de arte e historiador de formação de esquerda, pioneiro no debate racionalista na Itália, a partir de 1925 (CABRAL, 2019).

[...] E sobretudo não leve com você da cidade os ornamentos pretensiosos, os serviços citadinos. Ponha as suas flores do campo em vasos de terra, aparelhe a mesa simplesmente com a toalha branca, os copos de vidro grosso, fazendo com que sua casa permaneça com franca simplicidade em seu caráter, encontrarás uma calma, simples beleza, que dará serenidade e otimismo à sua nova vida. (BO E PAGANI, 1941, tradução nossa)

Decoração útil e duradoura: Abandone as pretensões dos estilos poeirentos: madeiras claras, construção forte, grande emprego de palha e cânhamo, linha simples e elegante, eis os móveis para a sua casa moderna. Até nas particulares "simplicidades", e nenhuma decoração banal empoeirada. A casa assim decorada atenderá à sua vida e hábitos modernos (BO, 1942a, tradução nossa).

A simplicidade também teve rebatimento no design pensado por Lina. Como típica arquiteta modernista, projetou diversos móveis durante sua carreira. O período de convivência com Gio Ponti possivelmente foi de grande influência estilística e formal. A simplicidade, neste caso, está presente nas formas puras, nos acabamentos modestos e na ausência de ornamentos.

Eis um pequeno móvel de trabalho de fácil execução e de grande praticidade, composto de um compartimento fixo e dois que abrem em movimento de compasso. O móvel construído em madeira comum é completamente revestido de cânhamo ou chita estampada com belas florezinhas vivazes. Passe esta página ao seu marceneiro e terás um gracioso móvel para a sua casa (BO, 1942b, tradução nossa).

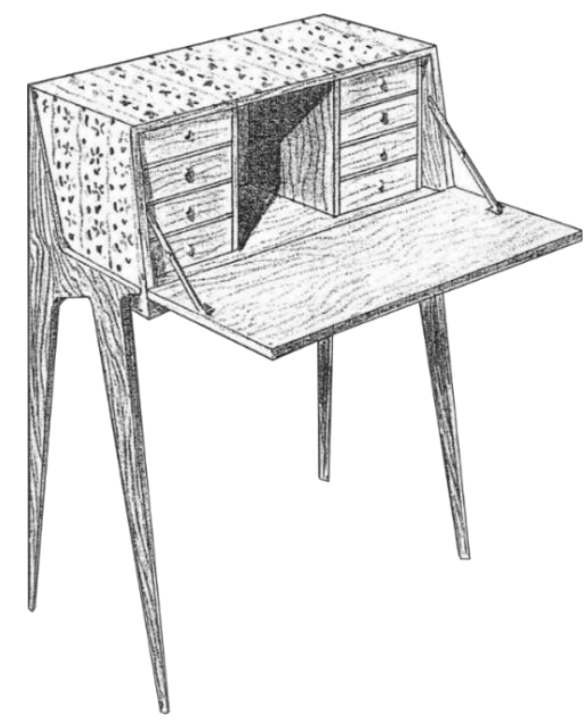

Figura 3. Uno scrittoio per signora. Elaborado por Lina Bo Bardi. Fonte: BO, 1942b. 
Pelas análises, percebe-se que o termo "simples" e seus derivados estão diretamente ligados ao racionalismo moderno, e também vinham associados a uma nova condição da urbanização das grandes cidades - os espaços cada vez menores e a decorrente necessidade de racionalização dos espaços, através de móveis multiuso.

Te oferecemos o meio de haver em casa uma escadinha, sempre útil para chegar "um pouco mais alto", uma escadinha que não ocupe muito espaço, mas esta não ocupa, porque... é uma cadeira! Os desenhos ilustram os movimentos da escadinha que da cadeira torna-se tal mediante um simples giro. Os desenhos que the damos são suficientes para a boa construção deste outro móvel para a casa campestre. Os móveis que desenhamos, as fotografias de decoração que te apresentamos, mesmo que não sejam hoje realizados, servem à formação do seu gosto para uma simples, clara, bela e serena casa de amanhã (ACHILLINA, 1943, tradução nossa).

Lina ambicionava voos maiores, para além dos textos e ilustrações nas revistas femininas. Quando começou a escrever para Domus, teve a oportunidade de abordar o que era discutido internacionalmente na arquitetura, como os cinco pontos corbusianos modernos. Não somente relacionadas a aspectos técnicos, as discussões refletem a preocupação com o social e a acomodação da classe trabalhadora nos espaços domésticos, indicando formas de baratear o custo das construções (LIMA, 2021).

A construção a esqueleto, com a abolição das paredes portantes, possibilitou uma grande flexibilidade no plano da decoração, e o processo lógico de construção é agora a maior liberdade na disposição dos ambientes; Abertos, separados por divisórias, facilmente transformáveis, fechando a decoração de modo não permanente enquanto um caráter de maior solidez aparente caracteriza as instalações permanentes: banheiros, toaletes, cozinhas, lavandarias e serviços em geral. Nem sempre paredes em alvenaria e divisórias permanentes formam separação entre ambientes, muitas vezes a separação é obtida mediante móveis profundos que formam paredes. A abolição das divisórias não estritamente necessárias é útil para o máximo rendimento do espaço ligado ao alto custo da construção (BO, 1944, tradução nossa).

Num último momento da fase italiana, Lina foi convidada pelo jornal Milano Sera a documentar locais destruídos pelos bombardeios da Segunda Guerra Mundial. Neste momento, fica mais evidente a formação humanista adquirida durante os anos em Milão, que estaria presente em sua produção no Brasil.

Paralelamente ao problema de construir milhares de alojamentos em um tempo relativamente curto, se apresenta o problema de mobiliá-los. Ou melhor, organizá-los para a vida que ali se deverá se desenvolver. 
As destruições, o desgaste dos móveis e das ferramentas que constituem o patrimônio da casa, verificados durante os anos de guerra, impõem uma revisão total do problema da organização doméstica; a organização que não é mais considerada hoje do ponto de vista exibicionista e decorativo, mas segundo um critério técnico, funcional (BO, 1945, tradução nossa).

\section{Considerações Finais}

Neste meio de debates sobre arquitetura, Lina via em Milão um ambiente ideologicamente adequado à sua visão de mundo, orientada politicamente à esquerda progressista. Na chamada fase italiana - entre 1940 e 1946, pode-se observar um amadurecimento intelectual e político na sua escrita, o que ocorreu à medida em que ganhava espaço e notoriedade em seu meio profissional. Os primeiros artigos, em sua maior parte da revista Grazia, são voltados à mulher dona de casa, e buscavam auxiliá-la a facilitar o dia a dia doméstico; os artigos tardios, como os da revista Domus, revelam uma preocupação com o social e com a reconstrução do país devastado pela guerra (CABRAL, 2019; LIMA, 2021).

Contudo, é recorrente em todo o período a menção à simplicidade, sempre ligada à economia das formas e uso de materiais econômicos e/ou de fácil manutenção, aspecto ligado à sua formação intelectual. A análise do corpus identificou em seu discurso o uso recorrente da palavra "simples" e suas variações e, na prática projetual, a proposição de materiais sóbrios e ausência de ornamentos. Em conjunto, estes elementos remetem a uma frequente busca por austeridade, por ambientes mais fáceis de manter limpos e organizados. Assim, a polissêmica simplicidade presente nos artigos pode ser entendida como expressão do racionalismo moderno instrumentalizado por Lina.

\section{Referências}

ABBAGNANO, Nicola. Dicionário de Filosofia. São Paulo: Martins Fontes, 2007. 1026 p. Tradução da 1a edição brasileira coordenada e revista por Alfredo Bosi. Revisão da tradução e tradução dos novos textos: Ivone Castilho Benedetti.

ACHILLINA. Economia di spazio. Grazia, Milão, n. 241, p.11, jun. 1943.

ANELLI, Renato Luiz Sobral. Ponderações sobre os relatos da trajetória de Lina Bo Bardi na Itália. Pós. Revista do Programa de Pós-graduação em Arquitetura e Urbanismo da Fauusp, São Paulo, v. 17, n. 27, p.86-101, 1 jun. 2010. Universidade de São Paulo Sistema Integrado de Bibliotecas - SIBiUSP. http://dx.doi.org/10.11606/issn.2317-2762.v0i27p86-101. Disponível em: <http://www.revistas.usp.br/posfau/article/view/43682>. Acesso em: 02 maio 2017.

BENEVOLO, Leonardo. História da arquitetura moderna. 3.ed. São Paulo: Perspectiva, 2004. 813 p.

BO, Lina. La Casa moderna - Attrezzatura e arredamento. Grazia, Milão, ano XVII, n. 201, p. 110-111, set. 1942a.

Un mobiletto da lavoro. Grazia, Milão, p.11-13, nov. 1942b.

. Sistemazione degli interni. Domus, Milão, p.199-208, 1944. 
. L'attrezzatura della casa. Milano Sera. Milão, ago. 1945.

BO, Lina; PAGANI, Carlo. Come organizzarsi in campagna durante lo sfollamento. Grazia, Milão, p.3133, 1941.

CABRAL, Maria Izabel Rego. Lina Bo Bardi, Architetto e Designer: um estudo de caso sobre a fase italiana (1939 -1946). Ponta Grossa: Atena, 2019. Disponível em:

https://www.atenaeditora.com.br/wp-content/uploads/2019/09/Lina-Bo-Bardi-Architetto-eDesigner_-Um-estudo-de-caso-sobre-a-fase-italiana-1939-1946.pdf. Acesso em: 04 maio 2020.

FERRAZ, Marcelo Carvalho (org.). Lina Bo Bardi. 5. ed. São Paulo: Romano Guerra, 2018. 336 p.

FRAMPTON, Kenneth. História crítica da arquitetura moderna. São Paulo: Martins Fontes, 2000.

GRINOVER, Marina Mange. Uma Ideia de Arquitetura: Escritos de Lina Bo Bardi. São Paulo:

Annablume, 2018. 296 p.

LIMA, Zeuler. Lina Bo Bardi: o que eu queria era ter história. São Paulo: Companhia das Letras, 2021.

MORA, José Ferrater. Diccionario de Filosofía. 5. ed. Buenos Aires: Montecasino, 1984. 2017 p.

PALLASMAA, Juhani. A complexidade da simplicidade: a estrutura interna da imagem artística. Ekstasis: Revista de Hermenêutica e Fenomenologia, [S.L.], v. 3, n. 1, set. 2014.

Universidade de Estado do Rio de Janeiro. http://dx.doi.org/10.12957/ek.2014.12793. Disponível em: https://www.researchgate.net/publication/276334780_A_complexidade_da_simplicidade_a_estrutu ra_interna_da_imagem_artistica. Acesso em: 27 nov. 2020.

UN LAVABO A tUTTI. A: Attualità, Architettura, Abitazione, Arte, Milão, n. 2, 1946. 